Theos experiments could only be carried on in the wards of hospital, and they would require a great sacrifice of time on the part of some zeelous student, competent to the task, who had time at command; but no greater service could be rendered to medical science, provided that due attention rere paid to the diet, and no purgative or other medicine be administered.

$$
\text { [To be continued.] }
$$

Alfred Place, Bedford Square.

\section{ON THE TREATMENT OF MANIA.}

\author{
By F. D. WALSH, Esq.
}

[Read bejore the Mridland Branch of the Provincial Medical and Surgical Association.]

THERE is probably no disease or imperfection of the human body which has been so little understood, or so badly treated, body which has been so little understood, or disease or imperfection which produces maniacal symptoms: indeed, we know nothing of any disease at all; it is only from symptoms which we see produced that we gire to a certain state of things the name of mania.

We cannot be surprised at the long-continued failure in the treatment of a disease of which we had not the slightest the treatment of a disease of which we had not the slightest cover errors of treatment-to the time when patients used to be bled about once a month, and chained up, starved, or whipped, in the interval; or else shut up in a dark room, with a hole in the door for their keepers to put a little food through, with instructions to mind their eyes, lest they should have the curiosity to take a peep at some naked, ragged, or dirty individuals, who would be almost certain to poke out their eyes for their curiosity. This system has happily passed away, but more recently than we are apt to believe; for, in a work written by one of our most eminent modern psychological writers, which I read a few years ago, I find instructions for attendants to take care of their faces when they fed patients through a hole in a door. The treatment of mania was certainly not understood when such instructions were giren; and these instructions, I have no doubt, would not be given by the same eminent authority at the present time.

But, to take a more recent period, which approaches nearly to the present time; it is but a very few years ago (1847) when the Commissioners in Lunacy published a Report, having first sent a circular to the superintendents of all the asylums in England and Wales, requesting information as to their treatment of various kinds of insanity and mania. In the replies of the several superintendents, wo certainly see a new light thrown upon the nature and treatment of mania. The nature of mania is becoming to be considered the very reverse of what it had been. We find some remarking that it is a disease of debility, requiring nutritious diet and exercise in the open air; yet the remedies used in 1847 are not adopted now ; or if, in some rare instances, they may be, they will certainly not be used some jears hence. They are generally too depressing, and not in accordance with the received theory that mania is a disease of debility. We find that, although general bleeding is given up, we have local bleeding; leeches to the forehead, the temples, and behind the ears; cupping on the back of the neck; counter-irritants, such as blisters, ointment of the tartrate of antimony, setons, even the actual cautery, and long gashes in the scalp; the use of emetics and strong cathartics, as croton oil. One gentleman only is mentioned as preferring gentle laxatives; strong cathartics being the general rule. We find also the use of several narcotics and sedatives, such as opium, henbane, conium, tartar emetic, and digitalis, with seclusion in a dark room, and a shared head. I cannot here enter upon the particular effect of each of these remedies; but am under the conviction, from pest experience, that they are the very things a case of mania does not require, and that they are generally injurious.
It appears from the Commissioners' Report, published in 1847 , that the medical officers of nearly all the asylums in this country were using some of these remedies. The Lincoln Lunatic Asylum was, however, an exception, in which it was said that nothing was done; for which it medical officers were severely criticised. It was in this same year (1847) that the then junior physician of the asylum became anxious to adopt more actire treatment, and was determined to try what medicine could do for the cure of mania.

There happened to be in the house at that time two violent cases of mania, a male and a female, both about the same age, and with very similar symptoms-a great propensity for muscular action, as jumping, dancing, breaking furniture and windows, raving obscenely, and with various delusions, tearing their clothing and bedding. The treatment of these cases, and the result, produced a strong impression on the medical officers and governors of the institution; and I propose to give some of the particulars of them-at least, of the male case.

CASE. was admitted on the 3rd of February, 1847, with apparent good bodily health, but subject to constipation. He had various mental delusions, raved obscenely on love matters, and fancied he had married a prostitute. He was very restless and active, dancing with great energy.

Fe was confined in a single-bedded infirmary, the room being darkened by closing the shutters. He took ten grains of calomel at night; and a saline mixture was also given. He danced in the room during the whole night, putting his body in all sorts of positions that would exercise muscular power; and raved on love matters.

Feb. 5th. He continued to rave incoherently, and to dance about the room.

Feb. 6th. He was much worse, and violent. He never remained in bed; he broke the windows, the table, and the top off the bedstead, in order, he said, to give him room to dance. He could not, he said, remain in bed by night or day. One grain of muriate of morphia was given, to be repeated at night.

Feb. 7th. The mania continued, and he took four grains of the muriate of morphia at intervals, in one-grain doses, but had no slesp. He had no sleep since the first night he came, when he took no morphia. He continued to brear the furniture, and danced abcut the room quite naked.

Feb. 8th. He complained of confinement and darkness. He took hyoscyamus with camphor, instead of the morphia.

Feb. 9th. He remained much in the same state.

Feb. 10th. The opium was tried again. A drachm of Battley's sedative solution was given every hour for the first six hours, without producing any effect but increased excitement. At 5 P.M. a three-drachm dose was tried, and repeated at nine o'clock, again at ten, and again at midnight, making in all sixteen drachms, without producin any sleep.

Feb. 11th. He was in a miserable state; tore his bedclothes, and strewed them about his room. He had bruised himself in various places. Besides dancing as usual, he commenced to knock his fists, his knees, and his feet, against the wall. Tro attendants were with him, to prevent him from doing this; but his knuckles were bleeding, and his knees bruised : his countenance had become anxious. I heard the attendants pitying him, and grumbling; saying, if they would only let the poor fellow out for about two or three hours, he would run it all off. Here the physician confessed that the opium and seclusion had failed. The patient was dressed; and the door of the room being opened, he rushed out in excessive joy, and began to dance as usual. I ordered a man to play the violin to him, and let him dance. After he had danced to the music, he sat down to rest; then danced again, until he began to be tired. He was then taken into the garden, where he ran and walked: he then said he was tired, and rather hungry. He had a mutton chop given him, and a pint of porter. He asked to go to bed; and slept during the night-the first sleep he had since his admission. 
Fob. 12th. He was excited, but became calm towards erening.

Feb. 13th. He slopt soundly during the night, and was more quiet; he danced in a harmless manner, and played at shittles and other active amusoments.

There scarcely need be noticed any more reports: he gradually got well, and made a most perfect recovery; and now holds a good position as a man of business.

I may mention here, that the female patient, a similar case, was treated also by opium ; but, when this failed, unfortunately, other remedies were tricd; she was bled behind the ears with leeches, and blistered. Digitalis was tried to 2 dangerous extent; so that we had some trouble to revive her by stimulants. Tartrate of antimony was rubbed on the back of her neck; a seton was put into her arm; she was kept in seclusion under treatment until she became pale and emaciated. She never recovered; and is at present an incurable case in the Lincoln County Asylum.

We may observe in the case of the male patient, that the commencement of improvement can be dated from the time he was allowed to leave his room, to omit opiates and erery kind of medicine, and to have liberal diet, consisting of the ordinary diet of the house, with extra meat for breakfast. This system of treatment was then peculiar to the Lincoln Lunatic Asylum; and was commented on, and much disapproved of, by the Commissioners in Lunacy, on their visit, which happened a little before this case; and they recommended, in a similar case, opium and seclusion ; but, except in the peculiar cases mentioned, no seclusion has been used in the asylum since 1841 : in fact, the treatment of mania with us is the very reverse of what it formerly was. Formerly, when patients were maniacal, an attempt was made to get them into a room; now an at tempt is made to get them into the open air. Formerly, an attempt was made to hold maniacal patients, and they became bruised by many strong attendants, and also put the attendants themselves in much danger; now the propensity for action in mania is considered as a means adapted by nature for the cure of the disease, and is encouraged and directed, but never restrained. Formerly, the quiet patients only were allowed to walk out, the more disorderly being kept in; but now, when the weather will scarcely permit of patients going out, the maniacal are taken into the open air, and encouraged to exercise: the attendants are willing to do this to save trouble, knowing that, if the patients have no exercise, they will have no sleep, and will be more troublesome the next day. They will therefore endeavour to exercise the maniacal patients, to sare them. selves trouble: and this fact says much for the system being a rational one.

The commissioners have changed their opinions of late with regard to opium and seclusion, and are now recommending exercise. I observe, in a Report on the Hanwell Asylum, they object to the disorderly patients being placed in the upper story of the house, saying they should be on the ground-floor, where they could have ready exercise in the air, and by this means subdue the excitement.

In the last Commissioners' Report of 1854 , there are also replies to an inquiry as to the use of restraint and seclusion. We find in this Report that the opinions of medical officers in the treatment of mania are for the most part very different from those of 1847 : in one of the replies, I find as follows:-

"The plan now adopted with a violent patient is to send him or her into the garden, in charge of one, or sometimes two attendants, with directions to walk them briskly through the grounds for an hour or two, or until they complain of being tired, or show an itclination to rest. Brisk exercise in the open air has been found a valuable means of subduing excitement, as well as procuring sleep, even after sedatives and narcotics have failed."

Such attendants should hsve instructions not to attempt to subdue excitement by holding the patient ; manual restraint being the most cruel kind of restraint of all, and also dangerous. We must not mind a fer eccentric actions, as running, leaping, or dancing, in a peculiar manner. If wach actions are encouraged and directed s bittle, tho per tients will generally become good-natured and exerciso themselves in a very harmlees manner. Many maniacs will dance when they hear music; this should always be encouraged; and there is generally some one who can play the violin, either amongst the patients or attendants. $f_{t}$ is supposed that there is a peculiar form of the disease called dancing mania, which is very common on the continent, particularly in Germany. A physician and superintendent of an asylum in Germany visited our institution, and very much disapproved of the system of non-restraint: he said also, in one form of mania you must restrain; and that is dancing mania. I had never seen it, but was told it consisted of violent dancing, striking, and kicking with such violence, that a patient was certain to do himself great injury; and his life would be in danger, unless he were completely restrained, bound hand and foot. The case of the male patient just related bears a strong resemblance to this peculiar form of mania: he had begun to injure himself, and put his life in danger; but was not cured by restraint, but by letting him dance. I have no doubt, many other cases of dancing mania could be produced by keeping them in a dark room, and administering opium, with no fresh air or healthy exercise; but allow them these, and they will very often cure themselves by indulging in those very actions which in former times were endeavoured to be restrained by all manner of cruel mechanical contrivances, or by seclusion and darkness, and many depressing medicines.

This system of curing mania, or rather of letting mania cure itself, is certainly founded on facts confirmed by many cases. Patients have been brought to the asylum, bound hand and foot, and corered with bruises. They had been for some months confined to their own rooms. The bruises were occasioned by attempts to hold them; but the violence increased. You may be told that no less than four or five people had been attempting to hold them for the last few days, and could do nothing with them. The patients have had their limbs untied, and set at liberty in spacious grounds: they began to enjoy their liberty, like a bird set free from a cage; but, in a few hours, the maniacal symptoms will be ameliorated, or in a few days will subside, or in a few weeks many patients will be recovered. I have known this to happen often; and, what may probably appear more singular, many patients have not had a single dose of medicine during their residence in the asylum.

Lineoln, December 1854.

\section{BIBLIOGRAPHICAT ITOTICES.}

0x Pais after Food : itg Cauges axd Treatuext. By EDTARD BALLARD, M.D.Lond., Licentiate of the Royal College of Physicians, etc. pp. 136. London: 1854.

Is this little work, Dr. BムLuARD has followed the somewhat unusual plan of taking into consideration an individual symptom, and pointing out the various diseased conditions which it indicates. This he has been led to do on the ground that " an accurate appreciation of individual symptoms lies at the base of all success in the diagnosis and cure of disease: and this appreciation is evidently important in the highest degree where a symptom, such as pain, is so prominent that it cannot be overlooked either by the petient or the physician."

After an introduction in which the digestive procese is briefly described, Dr. Ballard proceeds to the examination of various circumstances connected with the symptom, pain after food; viz., its seat, character, topographical distribution, connexion with quantity or quality of food or liquids, duration, means of relief, and accompanying phonomena, as tenderness on preseure, thirst, fererishneas romiting, eructations of watery or alimentary matters, temporary abdominal owelling, flatulent eructation, and borborygmi. These circumstances are here considered abeolutely, 